\title{
Challenges and Opportunities for Treating Intrahepatic Cholangiocarcinoma
}

\author{
Nikolaos Serifis' \\ Diamantis I Tsilimigras ${ }^{2}$ \\ Daniel J Cloonan ${ }^{3}$ \\ Timothy M Pawlik ${ }^{2}$ \\ 'Center for Transplantation Sciences, \\ Massachusetts General Hospital, Boston, \\ MA, USA; ${ }^{2}$ Department of Surgery, The \\ Ohio State University Wexner Medical \\ Center, Columbus, OH, USA; \\ ${ }^{3}$ Department of Surgery, Beth Israel \\ Deaconess Medical Center, Boston, \\ MA, USA
}

\begin{abstract}
Intrahepatic cholangiocarcinoma (ICC) is one of the rarest and most aggressive types of cancer. The symptoms of ICC patients can be vague, leading to late diagnosis and dismal prognosis. In this review, we investigated the treatment options for ICC, as well as ways to overcome challenges in identifying and treating this disease. Imaging remains the gold standard to diagnose ICC. Patients are staged based on the tumor, nodes and metastases (TNM) staging system. Patients eligible for surgical resection should undergo surgery with curative intent with the goal of microscopically disease-free margins (R0 resection) along with lymphadenectomy. Minimal invasive surgery (MIS) and liver transplantation have recently been offered as possible ways to improve disease outcomes. ICC recurrence is relatively common and, thus, most patients will need to be treated with systemic therapy. Several clinical trials have recently investigated the use of neoadjuvant (NT) and adjuvant therapies for ICC. NT may offer an opportunity to downsize larger tumors and provide patients, initially ineligible for surgery, with an opportunity for resection. NT may also treat occult micro-metastatic disease, as well as define tumor biology prior to surgical resection, thereby decreasing the risk for early postoperative recurrence. Adjuvant systemic therapy may improve outcomes of patients with ICC following surgery. Ongoing clinical trials are investigating new targeted therapies that hold the hope of improving long-term outcomes of patients with ICC.
\end{abstract}

Keywords: liver, intrahepatic cholangiocarcinoma, resection, outcomes

\section{Introduction}

Intrahepatic cholangiocarcinoma (ICC) is a rare, yet aggressive type of malignancy. ICC is the second most common cancer of the liver and accounts for $5-20 \%$ of all hepatic and $3 \%$ of all gastrointestinal malignancies. ${ }^{1,2}$ There are several risk factors associated with ICC, with the most important being biliary cysts, primary sclerosing cholangitis (PSC), hepatolithiasis, cirrhosis, viral hepatitis, parasitic infections and exposure to carcinogens. ${ }^{3}$ The vast majority of the cases, however, have no identifiable risk factor. From the aforementioned factors, hepatitis B has been strongly correlated to cirrhosis and development of poorly differentiated ICC. ${ }^{4}$ The number of ICC cases has been rising worldwide since the 1980s, with the highest numbers reported from Asia followed by many European countries and the United States of America. ${ }^{5}$ Although studies have also demonstrated that ICC is mostly prevalent among men, case numbers are becoming equally as common in both sexes. $^{5-7}$ Although most often diagnosed among older patients, recent data suggest an uptrend of ICC incidence among all age groups, even among patients younger than 45 years old. ${ }^{7}$
Correspondence: Diamantis I Tsilimigras Department of Surgery, The Ohio State University, Wexner Medical Center, 410 W IOth Avenue, Columbus, $\mathrm{OH}, 43210$, USA

Tel + I 2I59879177

Email diamantis.tsilimigras@osumc.edu 
Prognosis of patients with ICC has improved during the last decade yet still remains dismal, with an overall 5-year relative survival (OS) of only $9 \% .{ }^{2,8}$ Approximately only onethird of patients with ICC present with a tumor amenable to surgical resection. Even in resectable cases, 5-year OS ranges from only $20 \%$ to $35 \% .{ }^{9}$ Additionally, patients with unresectable ICC who receive palliative care treatment have a median survival of only 12.9 months. ${ }^{10}$ Unfortunately, recurrence of ICC occurs in up to $70 \%$ of patients during the first 5 years after curative-intent resection, data that emphasize the aggressiveness of the disease. ${ }^{9}$ In this review, we focus on the treatment options for ICC and the challenges that need to be overcome to improve prognosis of patients with ICC.

\section{Preoperative Evaluation Clinical Presentation}

Cholangiocarcinoma is typically defined as intrahepatic, perihilar and distal based on the anatomic location of the tumor (Figure 1). ${ }^{11}$ Not surprisingly, patients with ICC are less likely to present with biliary obstruction symptoms (jaundice, pruritus, dark urine, clay-colored stools) versus patients with perihilar cholangiocarcinoma and distal cholangiocarcinoma. Rather, ICC usually presents with abdominal pain, weight loss and malaise; these symptoms are often vague enough to be ignored by the patient, leading to late diagnosis of the disease and poor outcomes. ${ }^{12-14}$

\section{Laboratory Studies}

While ICC is primarily diagnosed through imaging and biopsy, it is important to evaluate liver enzymes, hepatic function, and tumor markers to facilitate diagnosis and inform treatment decisions. Several markers, including carbohydrate antigen 19-9 (CA 19-9), carcinoembryonic antigen (CEA) and alpha-fetoprotein (AFP) are helpful to distinguish ICC from HCC, as well as to monitor patients for recurrence of disease. Elevated levels of CA 19-9 have traditionally been associated with ICC, whereas AFP has generally been considered a marker specific to $\mathrm{HCC}^{15}$ Several studies have investigated whether these markers could be used preoperatively to identify patients at high risk for these cancers. ${ }^{16}$ For example, a study by Levy et al reported on the role of CA 19-9 among patients with PSC and cholangiocarcinoma. The authors proposed a cut-off value of $129 \mathrm{U} / \mathrm{mL}$ with a sensitivity of $78.6 \%$, specificity of $98.5 \%$, positive predictive value of $78.6 \%$, negative predictive value of $98.4 \%$, and accuracy of $97.1 \% .{ }^{17} \mathrm{In}$ a different study, by Moro et al, the authors reported that preoperative CA 19-9 and CEA could be used synergistically

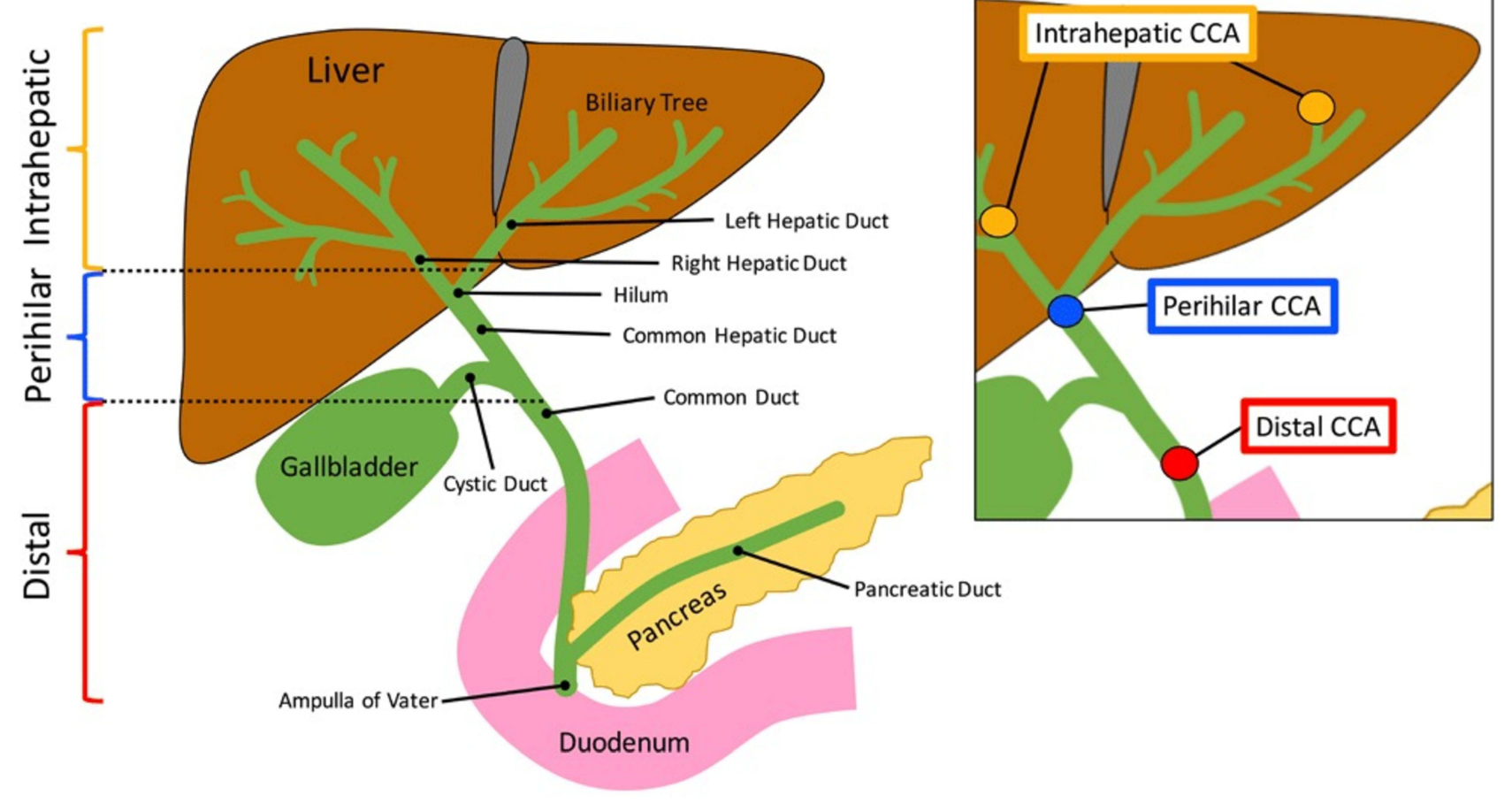

Figure I Anatomic locations of intrahepatic, perihilar and distal cholangiocarcinoma.

Notes: Reprinted from Kennedy L, Hargrove L, Demieville J et al. Recent Advances in Understanding Cholangiocarcinoma. FI000Research. 20I7;6:I8I8. (C) 20I7 Kennedy et al. Creative Commons Attribution Licence. ${ }^{\text {I }}$ 
as prognostic factors to predict OS with a cutoff of $176.3 \mathrm{IU} /$ $\mathrm{mL}$ for CA19-9 and $9.6 \mathrm{ng} / \mathrm{mL}$ for CEA. ${ }^{18}$ Specifically, patients with either a high CA19-9 and/or a high CEA had poor 1-year survival $(70.4 \%$ and $72.5 \%$, respectively). Despite these findings, CA 19-9 should not be used as the sole means of diagnosis, but only as an adjuvant confirmatory test as well as a marker of recurrence postoperatively.

\section{Imaging}

When a patient presents with signs and symptoms suspicious for hepatobiliary malignancy, imaging and, more specifically, ultrasound (US) is often the first method of assessment. US can potentially identify a source of abdominal pain or biliary obstruction. ${ }^{19}$ Contrastenhanced ultrasound (CEUS) can be used to differentiate HCC from ICC with $64.1 \%$ sensitivity, 97.4\% specificity and $73.6 \%$ accuracy. Features on CEUS suspicious for ICC include (1) arterial hyperenhancement with portal or late phase contrast washout, (2) no peripheral rim-like enhancement of the lesion, and (3) washout later than 43 seconds. ${ }^{20}$ While US may be helpful, a computed tomography (CT) scan and/or magnetic resonance imaging (MRI) should be routinely employed. On a contrastenhanced CT scan, ICC may appear with various enhancement patterns, including a peripheral rim-like contrast enhancement pattern during the arterial or portal phase, with a more attenuated center during the delayed phase 310 minutes after the contrast infusion. ${ }^{21,22}$ The contrastenhancement phase can potentially provide important information regarding the cell origin of the tumor and ultimately differentiate HCC from ICC. ${ }^{19} \mathrm{HCC}$ predominately originates from hepatocytes which receive their blood supply from the hepatic arteries and, as a result, it shows an arterial phase enhancement pattern on CT. ICC, on the other hand, a lesion of the hepatic parenchyma with desmoplastic features, receives its blood supply from the portal vein and this can explain the portal or, most frequently, the delayed phase enhancement pattern (Figure 2). ${ }^{19}$ It is worth noting that, while the hepatic arterial phase (HAP) is not the most common phase for an ICC to be identified on CT, the different HAP enhancement patterns have been correlated with the level of tumor spread and survival. There are three known patterns: hypovascular, rimlike and hypervascular. Hypovascular ICCs generally have the highest frequency of lymphatic, perineural and biliary invasion, as well as the worst survival at 1 and 3 years $\left(30.7 \%\right.$ and $0 \%$, respectively). ${ }^{23}$ Additionally, hypervascular tumors typically are associated with lower incidence of invasion and better survival at 1 and 3 years $\left(88.9 \%\right.$ and $66.7 \%$, respectively). ${ }^{23}$

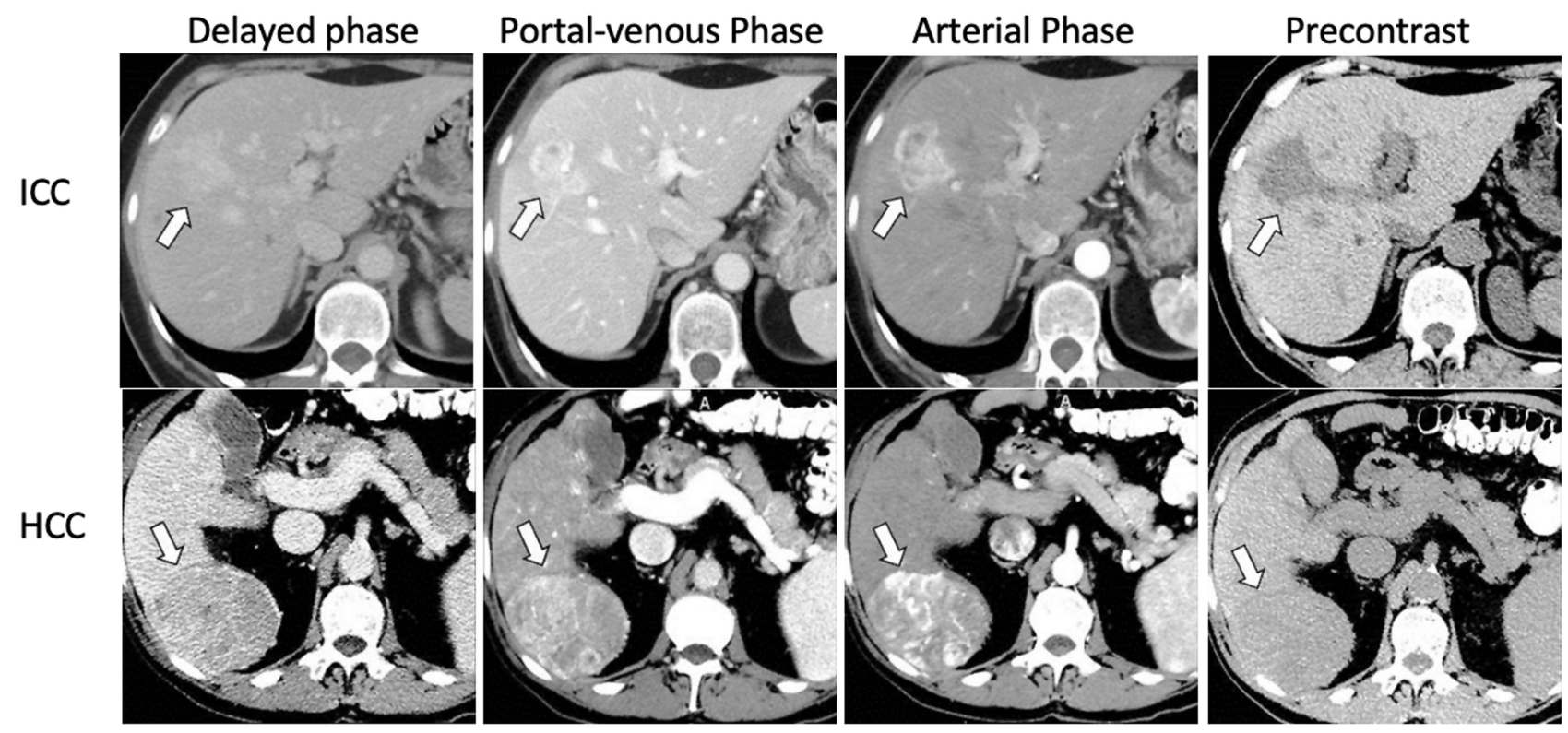

Figure 2 CT findings in ICC (upper row, white arrow) showing heterogenous contrast enhancement vs HCC (lower panel, white arrow) showing homogenous contrast enhancement followed by washout in the portal venous and delayed phases.

Notes: Reprinted from Blechacz B. Cholangiocarcinoma: Current knowledge and new developments. Gut and Liver. 20I7;II(I):13-26. (C) 20I7 by The Korean Society of Gastroenterology, the Korean Society of Gastrointestinal Endoscopy, the Korean Society of Neurogastroenterology and Motility, the Korean College of Helicobacter and Upper Gastrointestinal Research, the Korean Association of the Study of Intestinal Diseases, the Korean Association for the Study of the Liver, the Korean Pancreatobiliary Association, and the Korean Society of Gastrointestinal Cancer. Creative Commons Attribution Non-Commercial License (http://creativecommons.org/licenses/by-nc/4.0). ${ }^{107}$ 
During the initial evaluation of a patient suspicious for ICC, a contrast-enhanced MRI should be conducted. The enhancement characteristics of ICC are similar to those seen on CT; however, MRI is more able to detect the locoregional spread of the disease versus CT and, as such, MRI tends to be the preferred imaging modality at most centers. ${ }^{19}$ T1- and T2-weighted images, diffusion weighted images (DWI) and a magnetic resonance cholangiopancreatography (MRCP) should be reviewed. DWI, specifically, can increase the sensitivity needed to identify and differentiate ICC from other liver lesions. In particular, DWI often will demonstrate a pattern of rim enhancement during HAP, also known as a target sign, which is key in distinguishing ICC from HCC. ${ }^{1,19,22,24}$ An 18FFluoro-2-deoxy-D-glucose (FDG) integrated positron emission tomography (PET) scan may help identify metastases with more sensitivity and specificity than CT and MRI. As such, PET should be considered as an imaging modality in the preoperative staging of ICC. ${ }^{25}$ Of note, PET has a $95 \%$ sensitivity to detect resectable disease and an $89 \%$ sensitivity and $100 \%$ specificity to detect recurrent disease. Of note, biliary intraepithelial neoplasia, a precursor of periductal infiltrating ICC, is not well detected by imaging due to the microscopic alterations occurring in the biliary epithelium. ${ }^{26}$

\section{Staging}

A tumor, nodes and metastases (TNM) staging system for ICC was first introduced in 2010 in the American Joint Committee on Cancer (AJCC) staging manual in the 7th edition of their cancer staging manual. The data used to define this initial staging system were based on data from the Surveillance, Epidemiology, and End Results (SEER) registry. ${ }^{27,28}$ The 8 th edition incorporated several revisions including tumor size $(\leq 5 \mathrm{~cm}$ or $>5 \mathrm{~cm})$, reclassification of $\mathrm{T}$ categories and revision of lymph node metastasis stage from IVA to IIIB (Table 1). ${ }^{29-31}$ Several studies have confirmed the ability of the revised 8th edition to stratify patients relative to prognosis, yet the data have also indicated potential weaknesses. ${ }^{32-37}$ For instance, patients with tumors that perforated the visceral peritoneum, T3 tumors according to the 8th edition, survived longer than patients with T2 tumors. ${ }^{32-34,36}$ The extent of lymph node (LN) involvement has also been identified as an important

Table I AJCC Staging 7th and 8th Editions

\begin{tabular}{|c|c|c|c|}
\hline \multicolumn{2}{|c|}{ 7th AJCC Staging System for ICC } & \multicolumn{2}{|r|}{ 8th AJCC Staging System for ICC } \\
\hline TI & Solitary tumor without vascular invasion & $\mathrm{TI}$ & Solitary tumor without vascular invasion, $5 \leq \mathrm{cm}$, or $>5 \mathrm{~cm}$ \\
\hline $\mathrm{T} 2 \mathrm{a}$ & Solitary tumor with vascular invasion & Tla & Solitary tumor $5 \mathrm{~cm}$ without vascular invasion \\
\hline $\mathrm{T} 2 \mathrm{~b}$ & Multiple tumors, with or without vascular invasion & TIb & Solitary tumor $>5 \mathrm{~cm}$ without vascular invasion \\
\hline T3 & $\begin{array}{c}\text { Tumor perforating the visceral peritoneum or involving } \\
\text { structures by direct invasion }\end{array}$ & $\mathrm{T} 2$ & $\begin{array}{l}\text { Solitary tumor with intrahepatic vascular invasion or multiple tumors, } \\
\text { with or without vascular invasion }\end{array}$ \\
\hline T4 & Tumor with periductal invasion & T3 & Tumor perforating the visceral peritoneum \\
\hline No & No regional lymph node metastasis & T4 & Tumor involving local extrahepatic structures by direct invasion \\
\hline $\mathrm{NI}$ & Regional lymph node metastasis present & No & No regional lymph node metastasis \\
\hline Mo & No distant metastasis & NI & Regional lymph node metastasis present \\
\hline \multirow[t]{2}{*}{ MI } & Distant metastasis & Mo & No distant metastasis \\
\hline & & MI & Distant metastasis \\
\hline I & TINOMO & IA & TIaNOMO \\
\hline II & T2NOMO & IB & TIbNOMO \\
\hline III & T3NOMO & II & T2NOMO \\
\hline IVA & T4NoMo, TAnyNIMo & IIIA & T3NOMO \\
\hline \multirow[t]{2}{*}{ IVB } & TAnyNAnyMI & IIIB & T4NOM0, TAnyNIM0 \\
\hline & & IV & TAnyNAnyMI \\
\hline
\end{tabular}


prognostic factor among patients with ICC; in turn, the number of metastatic nodes should be taken into consideration relative to prognosis and stratification for surveillance purposes. ${ }^{38}$ Beyond the TNM AJCC staging, several nomograms have been developed to better predict the outcomes - some of which have demonstrated better accuracy than the AJCC Cancer Staging manual. ${ }^{39-42}$

The role of laparoscopy in staging has been controversial and debated. While some have advocated for staging laparoscopy due to a reported $27 \%$ to $38 \%$ incidence of detecting occult disease, others have cited the additional costs, extra time, and low yields associated with the procedure. ${ }^{43-46}$ Perhaps the best approach is the selective use of staging laparoscopy for patients with high-risk features such as high levels of CA 19-9 or equivocal imaging abnormalities.

\section{Surgical Resection \\ Assessment of Patient Status}

Before proceeding with a liver resection for ICC, a patient should be evaluated for their physiologic and anatomic status. In terms of the physiologic status of a surgical patient, several parameters have to be taken into consideration, including comorbidities and overall performance status. If comorbidities prohibit resection, alternative treatments should be offered, including systemic and/or locoregional therapies, as tolerated by the patient. ${ }^{16}$ The surgeon should evaluate both the function and size of the future liver remnant (FLR) to ensure adequate volume following a resection. The FLR should include at least two continuous segments with adequate perfusion, venous outflow, and biliary outflow. ${ }^{44}$ If FLR is inadequate, the risk of postoperative hepatic insufficiency (PHI) and other complications is considerably higher following resection. ${ }^{47-49}$ In general, FLR $>20 \%$ is sufficient among patients with normal underlying liver parenchyma, while $>30 \%$ is needed for patients with liver steatosis and $>40 \%$ for patients with liver cirrhosis. ${ }^{50-56}$ In addition to the FLR volume measurement, functional analysis of the liver with the indocyanine green clearance test or $99 \mathrm{mTc}-M e b r o f e n i n$ Hepatobiliary Scintigraphy may be helpful as a tool to assess preoperative liver function. ${ }^{51,57,58}$ For cases in which the FLR is not clearly adequate or even inadequate, portal vein embolization (PVE) can be used to induce hypertrophy of the contralateral lobe to facilitate a safer resection and postoperative course. ${ }^{59-61}$

\section{Resection Margins}

The ultimate goal of hepatic resection is to achieve microscopically disease-free margins (R0). This is not always feasible given the aggressiveness of the disease that leads to large invasive tumors at the time of diagnosis. Several groups have studied the correlation between the status of the resected surgical margins and patient outcomes. ${ }^{62-66}$ The ability to achieve an $\mathrm{R} 0$ resection has been reported to vary from $76 \%$ to $92 \%$, with the R0 rate generally around $80 \%$ at most experienced centers. Ribero et al reported that patients who had an R0 resection had better long-term outcomes versus patients who underwent an R1 resection; however, the width of the R0 margin was associated with survival. ${ }^{63}$ In another study, from Farges et al, patients with LN metastasis had similar outcomes after either an $\mathrm{R} 0$ or $\mathrm{R} 1$ resection. $^{62}$ These data suggested that once disease had spread to the regional lymph nodes, regional metastatic disease was a more important factor driving outcomes than local factors such as margin status. Of note, patients with no LN involvement generally have been noted to have better outcomes after an $\mathrm{R} 0$ resection, while prognosis among patients with LN metastatic disease are less impacted by the margin status relative to survival. To this point, among patients who had no LN involvement, margin width did affect long-term survival as patients with a negative margin width of $>10 \mathrm{~mm}$ had a better prognosis. ${ }^{62}$ Data from Tamandl et al and Shimada et al also demonstrated that margin width affected survival, but only in the presence/absence of certain prognostic factors. ${ }^{64,65}$ Spolverato et al reported a strong correlation between negative margin width and recurrence-free survival (RFS) as well as overall survival (OS), especially among patients with no nodal metastasis. ${ }^{66}$

To achieve an $\mathrm{R} 0$ resection, it may be necessary on occasion to perform a vascular resection in conjunction with the hepatectomy. When necessary to achieve an R0 margin, vascular resection should be employed. As Ali et al demonstrated, patients who had an R0 resection with vascular resection had comparable long-term outcomes to patients who had an $\mathrm{R} 0$ resection without the need for vascular resection. While these authors suggested that there was no difference between the two groups in terms of complications, these types of complex operation should only be performed at high-volume specialized centers. $^{67}$ To this point, a multi-institutional study of 1087 patients that included 128 patients who underwent vascular resection at high-volume centers noted no difference in complications or long-term survival compared with patients who underwent hepatectomy alone. ${ }^{68}$ 


\section{Lymphadenectomy}

While the National Comprehensive Cancer Network (NCCN) guidelines recommend routine lymphadenectomy as part of the surgical treatment of ICC, overall utilization of lymphadenectomy remains low. ${ }^{69,70}$ Zhang et al reported minimal increase in the number of patients who underwent lymphadenectomy (LND) from 2000 to 2013, noting that only roughly half of individuals had this procedure as part of their ICC surgery. ${ }^{71}$ The authors also noted a correlation with T-classification and risk of nodal disease, with the incidence of lymph node metastasis increasing with higher T-class disease. While the relation of T-classification and risk of lymph node metastasis was strong, it was not "linear" and even patients with early T-disease had a significant (10$20 \%$ ) incidence of nodal metastasis. Interestingly, while the overall utilization of lymphadenectomy among ICC patients has remained relatively stable over the last decade, there has been an increase in the number of nodes evaluated when a lymphadenectomy is performed. ${ }^{72,73}$ The proportion of patients with 6 or more lymph nodes evaluated still remains very low, resulting in only a subset of patients receiving guideline complaint lymph node evaluation $(18.8 \%){ }^{72}$ The importance of examining at least 6 LNs was demonstrated in a study by Zhang et al that noted markedly less stage migration among patients who had at least this number of nodes examined. ${ }^{73}$ In addition, the incidence of LNM was higher among patients who had a lymphadenectomy that involved nodal stations beyond only the hepatoduodenal ligament (Figure 3).

\section{Minimal Invasive Resection}

Minimal invasive surgery (MIS) has been increasingly utilized and may be associated with shorter length of stay and fewer complications versus an open approach. ${ }^{74}$ Specifically, MIS in the treatment of patients with ICC has been associated with fewer complications and a shorter LOS, yet no differences in long-term patient survival. ${ }^{75,76}$ While several studies have suggested a longer operative time for MIS versus open cases, a recent study by Lee et al noted shorter operative times, with lower utilization of the Pringle maneuver and less intraoperative blood loss with laparoscopic versus open resection of ICC. ${ }^{77}$ In addition, a meta-analysis study noted that patients undergoing an MIS approach were less likely to have a major resection and have the nodal basin evaluated; however, the incidence of R0 resection was comparable among the MIS versus open approach but fewer
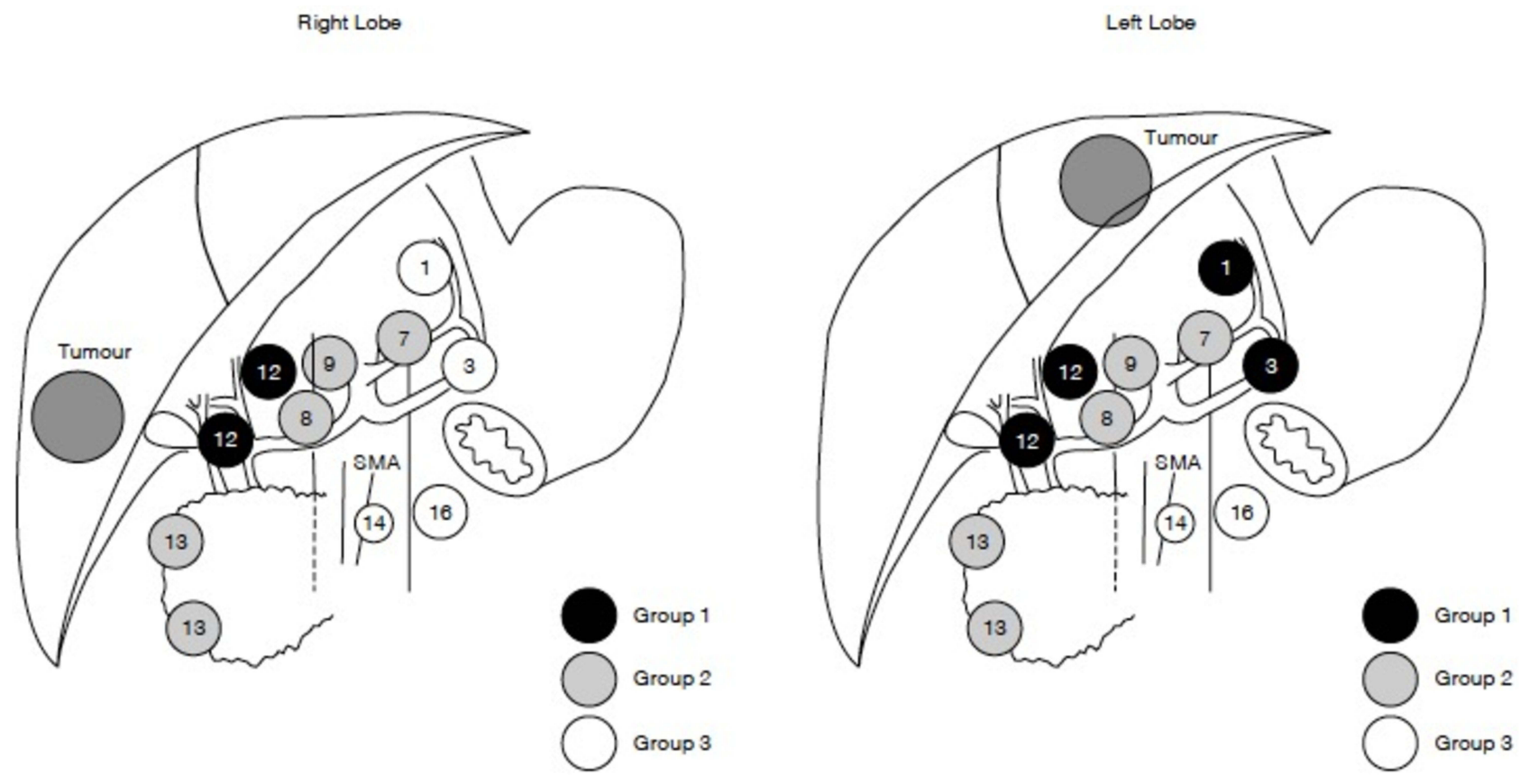

Figure 3 Grouping of regional lymph nodes according to the Classification of Primary Liver Cancer by the Liver Cancer Study Group of Japan. ${ }^{108}$ (I) Lymph nodes in the right cardial region; (3) lymph nodes along the lesser curvature of the stomach; (7) lymph nodes along the left gastric artery; (8) lymph nodes along the common hepatic artery; (9) lymph nodes along the coeliac artery; (12) lymph nodes in the hepatoduodenal ligament; (13) lymph nodes on the posterior surface of the pancreas head; (14) lymph nodes at the root of mesentery; (16) lymph nodes around the abdominal aorta. Group 3 lymph nodes are distant nodes beyond group 2 nodes. Reproduced with permission from Shimada M, Yamashita Y, Aishima S, Shirabe K, Takenaka K, Sugimachi K. Value of lymph node dissection during resection of intrahepatic cholangiocarcinoma. Br J Surg. 2001;88(II):1463-1466. Copyright (C 2002, Oxford University Press. ${ }^{109}$

Abbreviation: SMA, superior mesenteric artery. 
major hepatectomies and LNDs were performed with the MIS approach. ${ }^{78,79}$ In addition, the MIS approach is more often used for smaller tumors (mean $5 \mathrm{~cm}$ vs $6.4 \mathrm{~cm}$ in open cases) and the overall proportion of patients with at least 6 nodes examined as part of a lymphadenectomy was lower with the MIS approach. Collectively, results with MIS resection for ICC are associated with varied perioperative and oncologic outcomes with marked center variations. As such, MIS surgery for ICC should be centralized to surgeons and centers with high-volume experience.

\section{Transplantation}

Orthotopic liver transplantation is not standard of care treatment for ICC due to the poor outcomes and early recurrence of the disease. ${ }^{80}$ A 2008 study of 280 patients who underwent OLT for ICC noted a 1-year survival of $74 \%$ and 5 -year survival of $38 \%$, which were significantly worse than outcomes of patients who underwent OLT for HCC. $^{81}$ In a different study, Hong et al reported on 37 patients with ICC who were treated with either OLT or hepatectomy and noted that the OLT patients had better RFS at 3 and 5 years post-operatively compared with patients who had surgical resection (39\% vs $6 \%$ and $33 \%$ vs $0 \%$, respectively). ${ }^{82}$ Of note, the combination of neoadjuvant and adjuvant therapy was associated with improved 5-year OS versus patients who received no systemic therapy and only OLT. Sapisochin et al reported on 27 patients who had an OLT for ICC who were matched to patients who underwent transplantation for $\mathrm{HCC}^{83}$ Patients in the ICC group had worse RFS and OS at 1, 3 and 5 years post-OLT compared to individuals who had OLT for HCC. ${ }^{84}$ Interestingly, patients with ICC that was well or moderately differentiated and size $\leq 3 \mathrm{~cm}$ had a much better outcome following transplantation versus individuals who had tumors that were poorly differentiated and the same size. A different study of 13 patients with ICC who had OLT similarly noted that individuals with well-differentiated tumors had better RFS and OS than patients with moderately differentiated ICC. ${ }^{85}$ Overall, the use of OLT for ICC should only be performed in select circumstances at centers with protocols and registries to investigate the outcomes of OLT for ICC.

\section{Predictors of Outcomes}

Accurate prognostication of patients following surgical intervention is important. To this point, tumor burden, defined as the sum of the number of lesions and the natural logarithm of the tumor size $\left[\log _{\mathrm{e}}(\right.$ tumor size $)+$ number of lesions], has been proposed as an important predictor of outcomes for both primary and secondary hepatic malignancies. Our group has reported on the role of tumor burden as a predictor of outcomes among patients with ICC following surgical resection. ${ }^{86}$ Patients who had high tumor burden had the worse prognosis and also seemingly benefited the most from adjuvant chemotherapy. In a separate study, our group proposed a different prognostic score, LabScore, which is based only on preoperative laboratory markers, including platelets, CA 19-9 levels, albumin, and neutrophil-to-lymphocyte ratio (NLR). ${ }^{87}$ Stratifying patients using the LabScore (0-9, 10-19 and $\geq 20)$ meant we were able to differentiate risk of 5-year OS, disease-free survival (DFS) and early recurrence. Of note, patients with a higher LabScore generally had worse tumor characteristics and more advanced TNM disease stage. ICC has also been divided into different clusters/subtypes: common, proliferative and inflammatory according to tumor size, CA 19-9 and NLR. ${ }^{88}$ While patients with inflammatory ICC generally had the lowest CA 19-9 levels and smaller tumor size, these patients had high NLR and the worst OS, of only 13.3 months following curative-intent resection.

\section{Recurrent Disease: Incidence and Treatment}

Recurrence rates among patients with ICC remain high even after curative-intent treatment. In fact, more than half of the patients will present with recurrent disease within 5 years following curative intent resection. ${ }^{89}$ In a study of 933 patients, $73 \%$ of patients experienced recurrence, with $60 \%$ of individuals developing intrahepatic disease. ${ }^{9}$ Histopathologic features of ICC, such as large tumor size, multiple or satellite lesions, microvascular invasion and surgical margins width can predispose to early recurrence. Of note, patients with early recurrence often exhibited extrahepatic disease as the site of recurrence, while patients with late recurrence were more likely to have intrahepatic disease. Of note, patients with tumor $\geq 5 \mathrm{~cm}$, vascular invasion and LN involvement are at particular risk of poor outcomes, with a reported RFS of only 9 months. ${ }^{90}$

Among patients with recurrent ICC, resection can be entertained if technically feasible and the tumor has demonstrated good biology. In the setting of recurrent disease, systemic or locoregional therapy should be considered either prior to surgery or as an alternative. Among patients who have recurrent disease, a curative-intent therapeutic intervention is generally only feasible for 
individuals with intrahepatic recurrence, while patients with extrahepatic spread should typically receive chemotherapy. ${ }^{91}$ Of note, when patients can undergo hepatic resection of the recurrent lesion, the reported OS is about 26 months, while individuals who receive palliative care have a median OS of only 8 months. Differences in OS likely reflect the aggressiveness of the disease, as well as some selection bias.

\section{Non-Surgical Treatment Neoadjuvant Therapy}

There are several potential benefits associated with the use of preoperative chemotherapy, including downsizing the disease, selection of appropriate candidates for surgery, and potential prevention of early recurrence of ICC due to micro-metastatic disease present at the time of surgery. ${ }^{92}$ Two studies have reported conversion of locally advanced unresectable ICC into resectable disease; of note, OS among patients who underwent surgical resection after preoperative chemotherapy was similar to that of patients with resectable tumors who underwent initial resection. ${ }^{93,94}$ Currently, there is a phase II clinical trial examining the efficacy of gemcitabine cisplatin and Nabpaclitaxel as neoadjuvant therapy for ICC. ${ }^{95}$ Intra-arterial therapy (IAT) is another available option for unresectable ICC. In a study of 198 patients, IAT achieved partial or complete response in a subset of patients and resulted in stable disease for many others according to the mRECIST criteria. ${ }^{96}$ Selective internal radiation therapy (SIRT) has also been examined as a potential method to treat ICC. In one study, the authors noted no difference in OS among patients who underwent surgery for resectable tumors versus individuals with downsized disease either from chemotherapy or SIRT. ${ }^{97}$ The combination of systemic chemotherapy with hepatic artery infusion of chemotherapeutic agents has also been shown to induce tumor response in some patients with unresectable ICC. ${ }^{98}$

\section{Adjuvant Therapy}

A combination of surgical resection with systemic therapy is generally the treatment approach of choice for patients with ICC. $^{92}$ The PRODIGE $12-$ ACCORD 18 was a phase III randomized clinical trial that included 196 patients with biliary tract malignancies (BTM) from multiple centers in France who had undergone an R0 or R1 resection. ${ }^{99}$ The patients were randomly assigned to receive either gemcitabine and oxaliplatin chemotherapy (GEMOX) or surveillance only. Unfortunately, the trial failed to show any benefit in the treatment group for both RFS and OS. The BILCAP study was a stage III randomized multicenter trial from the UK that included 447 patients with BTM resections. ${ }^{100}$ Among these patients, a total of 84 individuals had ICC and were randomized to treatment with capecitabine or no adjuvant therapy. Although the DFS and RFS benefit in the treatment versus observation group only did not reach statistical significance, the extended survival offered to the treated patients may be relevant. Hence, recent guidelines have recommended capecitabine as adjuvant therapy for ICC. Two more clinical trials are ongoing. The ACTICCA-1 study is an international randomized phase III trial examining the combination of gemcitabine and cisplatin over observation alone in patients after resection with curative intent for BTM. ${ }^{101}$ The JCOG1202 study is a multicenter phase III randomized trial focusing on the effectiveness of S-1 over observation after surgical resection of BTM. ${ }^{102}$ While chemotherapy has not been very successful in treating ICC, targeted therapies are evolving as targets such as the endothelial growth factor receptor (EGFR) and signaling pathways involved in oncogenesis including KRAS and BRAF are identified. ${ }^{103,104}$

\section{Future Directions}

ICC is an aggressive type of cancer and systemic therapy has not been traditionally effective in treating this disease. As such, there is a need for more effective, targeted therapies. Several gene mutations have been identified as targets for therapeutic intervention, such as fibroblast growth factor receptor 2 (FGFR2) and isocitrate dehydrogenase 1 and 2 (IDH1, IDH2). FGFR2 mutations, which are detected in $10-15 \%$ of ICC patients, are almost exclusively found in ICC and tend to appear in young patients. ${ }^{105}$ IDH1 and IDH2 mutations found in $25 \%$ of patients with ICC are also mostly detected in the intrahepatic form of cholangiocarcinoma. ${ }^{106}$ A number of clinical trials have been conducted and even more are still ongoing in an effort to investigate the efficacy of targeted therapy to improve outcomes of patients with ICC.

\section{Conclusion}

ICC is a rare, potentially lethal malignancy that usually presents with vague symptoms at an advanced stage. Stateof-the-art imaging in combination with laboratory work-up should be performed to stage patients and plan therapeutic options. Systemic therapy is the treatment of choice for patients with advanced and unresectable disease, while 
locoregional options (ie SBIRT, TARE, HAI) can be considered. For patients with localized ICC that is resectable, hepatic resection with negative surgical margins and a lymphadenectomy with evaluation of $\geq 6$ nodes should be the standard of care. Adjuvant chemotherapy with capecitabine is highly recommended following surgical resection of ICC given the high incidence of post-operative recurrence and data reported by the BILPCAP trial. More studies are needed to establish the role of alternative treatment options, including transplantation, as well as targeted therapy in the treatment of patients with ICC.

\section{Disclosure}

The authors report no conflicts of interest in this work.

\section{References}

1. Beal EW, Tumin D, Moris D, et al. Cohort contributions to trends in the incidence and mortality of intrahepatic cholangiocarcinoma. Hepatobiliary Surg Nutr. 2018;7(4):270-276. doi:10.21037/hbsn. 2018.03.16

2. Wu L, Tsilimigras DI, Paredes AZ, et al. Trends in the incidence, treatment and outcomes of patients with intrahepatic cholangiocarcinoma in the USA: facility type is associated with margin status, use of lymphadenectomy and overall survival. World J Surg. 2019;43(7):1777-1787. doi:10.1007/s00268-019-04966-4

3. Khan SA, Tavolari S, Brandi G. Cholangiocarcinoma: epidemiology and risk factors. Liver Int. 2019;39(S1):19-31. doi:10.1111/ liv. 14095

4. Tao LY, He XD, Xiu DR. Hepatitis B virus is associated with the clinical features and survival rate of patients with intrahepatic cholangiocarcinoma. Clin Res Hepatol Gastroenterol. 2016;40 (6):682-687. doi:10.1016/j.clinre.2016.04.001

5. Florio AA, Ferlay J, Znaor A, et al. Global trends in intrahepatic and extrahepatic cholangiocarcinoma incidence from 1993 to 2012. Cancer. 2020;126(11):2666-2678. doi:10.1002/cncr.32803

6. Brown KM, Parmar AD, Geller DA. Intrahepatic cholangiocarcinoma. Surg Oncol Clin N Am. 2014;23 (2):231-246. doi:10.1016/j.soc.2013.10.004

7. Van Dyke AL, Shiels MS, Jones GS, et al. Biliary tract cancer incidence and trends in the United States by demographic group, 1999-2013. Cancer. 2019;125(9):1489-1498. doi:10.1002/ cncr.31942

8. Howlader N, Noone AM, Krapcho M, et al. SEER cancer statistics review, 1975-2017. Based on November 2019 SEER Data Submission. Bethesda, MD: National Cancer Institute; 2020. Available from: Https://Seer.Cancer.Gov/Csr/1975_2017/. Accessed September 23, 2021

9. Zhang XF, Beal EW, Bagante F, et al. Early versus late recurrence of intrahepatic cholangiocarcinoma after resection with curative intent. Br J Surg. 2018;105(7):848-856. doi:10.1002/bjs. 10676

10. Dhanasekaran R, Hemming AW, Zendejas I, et al. Treatment outcomes and prognostic factors of intrahepatic cholangiocarcinoma Oncol Rep. 2013;29(4):1259-1267. doi:10.3892/or.2013.2290

11. Kennedy L, Hargrove L, Demieville J, et al. Recent advances in understanding cholangiocarcinoma. F1000Res. 2017;6:1818. doi:10.12688/f1000research.12118.1

12. Blechacz B, Komuta M, Roskams T, Gores GJ. Clinical diagnosis and staging of cholangiocarcinoma. Nat Rev Gastroenterol Hepatol. 2011;8(9):512-522. doi:10.1038/nrgastro.2011.131
13. El Rassi Z, Partensky C, Scoazec JY, Henry L, Lombard-Bohas C, Maddern G. Peripheral cholangiocarcinoma: presentation, diagnosis, pathology and management. Eur J Surg Oncol. 1999;25(4):375-380. doi:10.1053/ejso.1999.0660

14. DeOliveira ML, Cunningham SC, Cameron JL, et al. Cholangiocarcinoma: thirty-one-year experience with 564 patients at a single institution. Ann Surg. 2007;245(5):755-762. doi:10.1097/01.sla.0000251366.62632.d3

15. Tao LY, Cai L, He XD, Liu W, Qu Q. Comparison of serum tumor markers for intrahepatic cholangiocarcinoma and hepatocellular carcinoma. Am Surg. 2010;76(11):1210-1213. doi:10.1177/00 0313481007601119

16. El-Diwany R, Pawlik TM, Ejaz A. Intrahepatic cholangiocarcinoma. Surg Oncol Clin N Am. 2019;28(4): 587-599. doi:10.1016/j.soc.2019.06.002

17. Levy C, Lymp J, Angulo P, Gores GJ, Larusso N, Lindor KD. The value of serum CA 19-9 in predicting cholangiocarcinomas in patients with primary sclerosing cholangitis. Dig Dis Sci. 2005;50 (9):1734-1740. doi:10.1007/s10620-005-2927-8

18. Moro A, Mehta R, Sahara K, et al. The impact of preoperative CA19-9 and CEA on outcomes of patients with intrahepatic cholangiocarcinoma. Ann Surg Oncol. 2020;27(8):2888-2901. doi:10.1245/s10434-020-08350-8

19. Fábrega-Foster K, Ghasabeh Ma, Pawlik TM, Kamel IR. Multimodality imaging of intrahepatic cholangiocarcinoma. Hepatobiliary Surg Nutr. 2017;6(2):67-78. doi:10.21037/hbsn. 2016.12.10

20. Liu GJ, Wang W, Lu MD, et al. Contrast-enhanced ultrasound for the characterization of hepatocellular carcinoma and intrahepatic cholangiocarcinoma. Liver Cancer. 2015;4(4):241-252. doi:10. $1159 / 000367738$

21. Valls $\mathrm{C}$, Gumà $\mathrm{A}$, Puig $\mathrm{I}$, et al. Intrahepatic peripheral cholangiocarcinoma: CT evaluation. Abdom Imaging. 2000;25(5):490-496. doi:10.1007/s002610000079

22. Seo N, Kim DY, Choi JY. Cross-sectional imaging of intrahepatic cholangiocarcinoma: development, growth, spread, and prognosis. Am J Roentgenol. 2017;209(2):W64-W75. doi:10.22 14/AJR.16.16923

23. Fujita N, Asayama Y, Nishie A, et al. Mass-forming intrahepatic cholangiocarcinoma: enhancement patterns in the arterial phase of dynamic hepatic CT - correlation with clinicopathological findings. Eur Radiol. 2017;27(2):498-506. doi:10.1007/s00330016-4386-3

24. Rimola J, Forner A, Reig M, et al. Cholangiocarcinoma in cirrhosis: absence of contrast washout in delayed phases by magnetic resonance imaging avoids misdiagnosis of hepatocellular carcinoma. Hepatology. 2009;50(3):791-798. doi:10.1002/hep.23071

25. Corvera CU, Blumgart LH, Akhurst T, et al. $18 \mathrm{~F}$ fluorodeoxyglucose positron emission tomography influences management decisions in patients with biliary cancer. $J \mathrm{Am}$ Coll Surg. 2008;206(1):57-65. doi:10.1016/j.jamcollsurg.2007.07.002

26. Joo I, Lee JM. Imaging bile duct tumors: pathologic concepts, classification, and early tumor detection. Abdom Imaging. 2013;38(6):1334-1350. doi:10.1007/s00261-013-0027-3

27. Edge SB, Compton CC. The American joint committee on cancer: the 7 th edition of the AJCC cancer staging manual and the future of TNM. Ann Surg Oncol. 2010;17(6):1471-1474. doi:10.1245/ s10434-010-0985-4

28. Nathan H, Aloia TA, Vauthey JN, et al. A proposed staging system for intrahepatic cholangiocarcinoma. Ann Surg Oncol. 2009;16(1):14-22. doi:10.1245/s10434-008-0180-z

29. Amin MB, Edge S, Greene F, et al. AJCC Cancer Staging Manual. 8th ed. American College of Surgeons; 2017.

30. Lee AJ, Chun YS. Intrahepatic cholangiocarcinoma: the AJCC/ UICC 8th edition updates. Chin Clin Oncol. 2018;7(5):9-11. doi:10.21037/cco.2018.07.03 
31. Yuan L, Luo X, Lu X, Huang B, Cai Q. Liver resection for intrahepatic cholangiocarcinoma in AJCC-stage IV: an evaluation of the survival benefit and prognostic accuracy of current AJCC staging system on N and M classification. Oncol Rep. 2016;36 (5):2663-2672. doi:10.3892/or.2016.5103

32. Spolverato G, Bagante F, Weiss M, et al. Comparative performances of the 7th and the 8th editions of the American Joint Committee on Cancer staging systems for intrahepatic cholangiocarcinoma. J Surg Oncol. 2017;115(6):696-703. doi: $10.1002 /$ jso. 24569

33. Kang SH, Hwang S, Lee YJ, et al. Prognostic comparison of the 7th and 8th editions of the American Joint Committee on Cancer staging system for intrahepatic cholangiocarcinoma. $J$ Hepatobiliary Pancreat Sci. 2018;25(4):240-248. doi:10.1002/jhbp.543

34. Sasaki K, Margonis GA, Andreatos N, et al. Serum tumor markers enhance the predictive power of the AJCC and LCSGJ staging systems in resectable intrahepatic cholangiocarcinoma. HPB. 2018;20(10):956-965. doi:10.1016/j.hpb.2018.04.005

35. Uenishi T, Ariizumi S, Aoki T, et al. Proposal of a new staging system for mass-forming intrahepatic cholangiocarcinoma: a multicenter analysis by the Study Group for Hepatic Surgery of the Japanese Society of Hepato-Biliary-Pancreatic Surgery. J Hepatobiliary Pancreat Sci. 2014;21(7):499-508. doi:10.1002/jhbp.92

36. Cheng Z, Lei Z, Si A, et al. Modifications of the AJCC 8th edition staging system for intrahepatic cholangiocarcinoma and proposal for a new staging system by incorporating serum tumor markers. HPB. 2019;21(12):1656-1666. doi:10.1016/j.hpb.2019.05.010

37. Kim Y, Moris DP, Zhang XF, et al. Evaluation of the 8th edition American Joint Commission on Cancer (AJCC) staging system for patients with intrahepatic cholangiocarcinoma: a surveillance, epidemiology, and end results (SEER) analysis. J Surg Oncol. 2017;116(6):643-650. doi:10.1002/jso.24720

38. Zhang XF, Xue F, He J, et al. Proposed modification of the eighth edition of the AJCC staging system for intrahepatic cholangiocarcinoma. HPB. 2021. doi:10.1016/j.hpb.2021.02.009

39. Ma K, Dong B, Wang L, et al. Nomograms for predicting overall survival and cancer-specific survival in patients with surgically resected intrahepatic cholangiocarcinoma. Cancer Manag Res. 2019;11:6907-6929. doi:10.2147/CMAR.S212149

40. Shen $\mathrm{H}$, Zhang S, Xia Y, et al. A nomogram in predicting risks of intrahepatic cholangiocarcinoma after partial hepatectomy for hepatolithiasis. J Gastrointest Surg. 2021. doi:10.1007/s11605021-04947-w

41. Wang Y, Li J, Xia Y, et al. Prognostic nomogram for intrahepatic cholangiocarcinoma after partial hepatectomy. J Clin Oncol. 2013;31(9):1188-1195. doi:10.1200/JCO.2012.41.5984

42. Hyder O, Marques H, Pulitano C, et al. A nomogram to predict long-term survival after resection for intrahepatic cholangiocarcinoma: an Eastern and Western experience. JAMA Surg. 2014;149 (5):432-438. doi:10.1001/jamasurg.2013.5168

43. D'Angelica M, Fong Y, Weber S, et al. The role of staging laparoscopy in hepatobiliary malignancy: prospective analysis of 401 cases. Ann Surg Oncol. 2003;10(2):183-189. doi:10.1245/ ASO.2003.03.091

44. Weber SM, Ribero D, O’Reilly EM, Kokudo N, Miyazaki M, Pawlik TM. Intrahepatic cholangiocarcinoma: expert consensus statement. HPB. 2015;17(8):669-680. doi:10.1111/hpb.12441

45. Weber SM, Jarnagin WR, Klimstra D, DeMatteo RP, Fong Y, Blumgart LH. Intrahepatic cholangiocarcinoma: resectability, recurrence pattern, and outcomes. J Am Coll Surg. 2001;193 (4):384-391. doi:10.1016/S1072-7515(01)01016-X

46. Goere D, Wagholikar GD, Pessaux P, et al. Utility of staging laparoscopy in subsets of biliary cancers: laparoscopy is a powerful diagnostic tool in patients with intrahepatic and gallbladder carcinoma. Surg Endosc Other Interv Tech. 2006;20 (5):721-725. doi:10.1007/s00464-005-0583-x
47. Nagino M, Kamiya J, Nishio H, Ebata T, Arai T, Nimura Y. Two hundred forty consecutive portal vein embolizations before extended hepatectomy for biliary cancer: surgical outcome and long-term follow-up. Ann Surg. 2006;243(3):364-372. doi:10.1097/01.sla.0000201482.11876.14

48. Van Den Broek MAJ, Olde Damink SWM, Dejong CHC, et al. Liver failure after partial hepatic resection: definition, pathophysiology, risk factors and treatment. Liver Int. 2008;28(6):767-780. doi:10.1111/j.1478-3231.2008.01777.x

49. Chakedis J, Squires MH, Beal EW, et al. Update on current problems in colorectal liver metastasis. Curr Probl Surg. 2017;54(11):554-602. doi:10.1067/j.cpsurg.2017.10.002

50. Abdalla EK, Barnett CC, Doherty D, Curley SA, Vauthey JN. Extended hepatectomy in patients with hepatobiliary malignancies with and without preoperative portal vein embolization. Arch Surg. 2002;137(6):675-681. doi:10.1001/archsurg.137.6. 675

51. Vauthey JN, Chaoui A, Do KA, et al. Standardized measurement of the future liver remnant prior to extended liver resection: methodology and clinical associations. Surgery. 2000;127(5): 512-519. doi:10.1067/msy.2000.105294

52. Kubota K, Makuuchi M, Kusaka K, et al. Measurement of liver volume and hepatic functional reserve as a guide to decision-making in resectional surgery for hepatic tumors. Hepatology. 1997;26(5):1176-1181. doi:10.1002/hep.510260514

53. Thirunavukarasu P, Aloia TA. Preoperative assessment and optimization of the future liver remnant. Surg Clin North Am. 2016;96(2):197-205. doi:10.1016/j.suc.2015.11.001

54. Abdalla EK. Resection of colorectal liver metastases. J Gastrointest Surg. 2011;15(3):416-419. doi:10.1007/s11605011-1429-6

55. Shindoh J, Tzeng CWD, Aloia TA, et al. Optimal future liver remnant in patients treated with extensive preoperative chemotherapy for colorectal liver metastases. Ann Surg Oncol. 2013;20(8):2493-2500. doi:10.1245/s10434-012-2864-7

56. Zorzi D, Laurent A, Pawlik TM, Lauwers GY, Vauthey JN, Abdalla EK. Chemotherapy-associated hepatotoxicity and surgery for colorectal liver metastases. Br J Surg. 2007;94(3):274-286. doi:10.1002/bjs.5719

57. Simpson AL, Geller DA, Hemming AW, et al. Liver planning software accurately predicts postoperative liver volume and measures early regeneration. J Am Coll Surg. 2014;219(2):199-207. doi:10.1016/j.jamcollsurg.2014.02.027

58. Hoekstra LT, De Graaf W, Nibourg GAA, et al. Physiological and biochemical basis of clinical liver function tests: a review. Ann Surg. 2013;257(1):27-36. doi:10.1097/SLA.0b013e31825d5d47

59. Cieslak KP, Huisman F, Bais T, et al. Future remnant liver function as predictive factor for the hypertrophy response after portal vein embolization. Surgery. 2017;162(1):37-47. doi:10.1016/j. surg.2016.12.031

60. Kosuge T, Makuuchi M, Takayama T, et al. [Preoperative portal embolization increases safety of hepatectomy]. Nihon Geka Gakkai Zasshi. 1991;92(9):1320-1323. Japanese.

61. Ribero D, Chun YS, Vauthey JN. Standardized liver volumetry for portal vein embolization. Semin Intervent Radiol. 2008;25 (2):104-109. doi:10.1055/s-2008-1076681

62. Farges O, Fuks D, Boleslawski E, et al. Influence of surgical margins on outcome in patients with intrahepatic cholangiocarcinoma: a multicenter study by the AFC-IHCC-2009 study group. Ann Surg. 2011;254(5):824-830. doi:10.1097/SLA.0b013e3182 $36 \mathrm{c} 21 \mathrm{~d}$

63. Ribero D, Pinna AD, Guglielmi A, et al. Surgical approach for long-term survival of patients with intrahepatic cholangiocarcinoma: a multi-institutional analysis of 434 patients. Arch Surg. 2012;147(12):1107-1113. doi:10.1001/archsurg.2012. 1962 
64. Tamandl D, Herberger B, Gruenberger B, Puhalla H, Klinger M, Gruenberger $\mathrm{T}$. Influence of hepatic resection margin on recurrence and survival in intrahepatic cholangiocarcinoma. Ann Surg Oncol. 2008;15(10):2787-2794. doi:10.1245/s10434-0080081-1

65. Shimada K, Sano T, Sakamoto Y, Esaki M, Kosuge T, Ojima H. Clinical impact of the surgical margin status in hepatectomy for solitary mass-forming type intrahepatic cholangiocarcinoma without lymph node metastases. J Surg Oncol. 2007;96(2):160-165. doi:10.1002/jso.20792

66. Spolverato G, Yakoob MY, Kim Y, et al. The impact of surgical margin status on long-term outcome after resection for intrahepatic cholangiocarcinoma. Ann Surg Oncol. 2015;22(12):40 20-4028. doi:10.1245/s10434-015-4472-9

67. Ali SM, Clark CJ, Zaydfudim VM, Que FG, Nagorney DM. Role of major vascular resection in patients with intrahepatic cholangiocarcinoma. Ann Surg Oncol. 2013;20(6):2023-2028. doi:10.1245/s10434-012-2808-2

68. Reames BN, Ejaz A, Koerkamp BG, et al. Impact of major vascular resection on outcomes and survival in patients with intrahepatic cholangiocarcinoma: a multi-institutional analysis. J Surg Oncol. 2017;116(2):133-139. doi:10.1002/ jso. 24633

69. Zhang XF, Lv Y, Weiss M, et al. Should utilization of lymphadenectomy vary according to morphologic subtype of intrahepatic cholangiocarcinoma? Ann Surg Oncol. 2019;57:2242-2250. doi:10.1245/s10434-019-07336-5

70. NCCN clinical practice guidelines in oncology (NCCN guidelines ${ }^{\mathbb{B}}$ ) hepatobiliary cancers; 2021. Available from: https://www.nccn.org/professionals/physician_gls/pdf/hepatobili ary.pdf. Accessed September 23, 2021.

71. Zhang XF, Chen Q, Kimbrough CW, et al. Lymphadenectomy for intrahepatic cholangiocarcinoma: has nodal evaluation been increasingly adopted by surgeons over time? A national database analysis. J Gastrointest Surg. 2018;22(4):668-675. doi:10.1007/ s11605-017-3652-2

72. Zhang XF, Chakedis J, Bagante F, et al. Trends in use of lymphadenectomy in surgery with curative intent for intrahepatic cholangiocarcinoma. Br J Surg. 2018;105(7):857-866. doi:10.1002/ bjs. 10827

73. Zhang XF, Xue F, Dong DH, et al. Number and station of lymph node metastasis after curative-intent resection of intrahepatic cholangiocarcinoma impact prognosis. Ann Surg. 2020. doi:10. 1097/sla.0000000000003788

74. Ejaz A, Sachs T, He J, et al. A comparison of open and minimally invasive surgery for hepatic and pancreatic resections using the nationwide inpatient sample. Surgery. 2014;156(3):538-547. doi:10.1016/j.surg.2014.03.046

75. Wu J, Han J, Zhang Y, et al. Safety and feasibility of laparoscopic versus open liver resection with associated lymphadenectomy for intrahepatic cholangiocarcinoma. Biosci Trends. 2020;14(5): 376-383. doi: $10.5582 /$ bst.2020.03293

76. Zhu Y, Song J, Xu X, Tan Y, Yang J. Safety and feasibility of laparoscopic liver resection for patients with large or multiple intrahepatic cholangiocarcinomas: a propensity score based case-matched analysis from a single institute. Medicine. 2019;98 (49). doi:10.1097/MD.0000000000018307

77. Lee W, Park JH, Kim JY, et al. Comparison of perioperative and oncologic outcomes between open and laparoscopic liver resection for intrahepatic cholangiocarcinoma. Surg Endosc. 2016;30 (11):4835-4840. doi:10.1007/s00464-016-4817-x

78. Wei F, Wang G, Ding J, Dou C, Yu T, Zhang C. Is it time to consider laparoscopic hepatectomy for intrahepatic cholangiocarcinoma? A meta-analysis. $J$ Gastrointest Surg. 2020;24 (10):2244-2250. doi:10.1007/s11605-019-04404-9
79. Martin SP, Drake J, Wach MM, et al. Laparoscopic approach to intrahepatic cholangiocarcinoma is associated with an exacerbation of inadequate nodal staging. Ann Surg Oncol. 2019;26 (6):1851-1857. doi:10.1245/s10434-019-07303-0

80. Goldaracena N, Gorgen A, Sapisochin G. Current status of liver transplantation for cholangiocarcinoma. Liver Transplant. 2018;24(2):294-303. doi:10.1002/1t.24955

81. Becker NS, Rodriguez JA, Barshes NR, O’Mahony CA, Goss JA, Aloia TA. Outcomes analysis for 280 patients with cholangiocarcinoma treated with liver transplantation over an 18-year period. $J$ Gastrointest Surg. 2008;12(1):117-122. doi:10.1007/s11605007-0335-4

82. Hong JC, Jones CM, Duffy JP, et al. Comparative analysis of resection and liver transplantation for intrahepatic and hilar cholangiocarcinoma: a 24-year experience in a single center. Arch Surg. 2011;146(6):683-689. doi:10.1001/archsurg.2011.116

83. Sapisochin G, De Lope CR, Gastaca M, et al. Intrahepatic cholangiocarcinoma or mixed hepatocellular-cholangiocarcinoma in patients undergoing liver transplantation: a Spanish matched cohort multicenter study. Ann Surg. 2014;259(5):944-952. doi:10.1097/SLA.0000000000000494

84. Sapisochin G, Facciuto M, Rubbia-Brandt L, et al. Liver transplantation for "very early" intrahepatic cholangiocarcinoma: international retrospective study supporting a prospective assessment. Hepatology. 2016;64(4):1178-1188. doi:10.1002/hep.28744

85. Takahashi K, Obeid J, Burmeister CS, et al. Intrahepatic cholangiocarcinoma in the liver explant after liver transplantation: histological differentiation and prognosis. Ann Transplant. 2016;21:208-215. doi:10.12659/AOT.895936

86. Tsilimigras DI, Hyer JM, Paredes AZ, et al. Tumor burden dictates prognosis among patients undergoing resection of intrahepatic cholangiocarcinoma: a tool to guide post-resection adjuvant chemotherapy? Ann Surg Oncol. 2021;28(4):1970-1978. doi:10.1245/s10434-020-09393-7

87. Tsilimigras DI, Mehta R, Aldrighetti L, et al. Development and validation of a laboratory risk score (LabScore) to predict outcomes after resection for intrahepatic cholangiocarcinoma. $J$ Am Coll Surg. 2020;230(4):381-391.e2. doi:10.1016/j.jamcollsurg.2019.12.025

88. Tsilimigras DI, Hyer JM, Paredes AZ, et al. A novel classification of intrahepatic cholangiocarcinoma phenotypes using machine learning techniques: an international multi-institutional analysis. Ann Surg Oncol. 2020;27(13):5224-5232. doi:10.1245/s10434020-08696-z

89. Squires MH, Cloyd JM, Dillhoff M, Schmidt C, Pawlik TM. Challenges of surgical management of intrahepatic cholangiocarcinoma. Expert Rev Gastroenterol Hepatol. 2018;12 (7):671-681. doi:10.1080/17474124.2018.1489229

90. Hyder O, Hatzaras I, Sotiropoulos GC, et al. Recurrence after operative management of intrahepatic cholangiocarcinoma. Surgery. 2013;153(6):811-818. doi:10.1016/j.surg.2012.12.005

91. Spolverato G, Kim Y, Alexandrescu S, et al. Management and outcomes of patients with recurrent intrahepatic cholangiocarcinoma following previous curative-intent surgical resection. Ann Surg Oncol. 2016;23(1):235-243. doi:10.1245/s10434-015-4642-9

92. Akateh C, Ejaz AM, Pawlik TM, Cloyd JM. Neoadjuvant treatment strategies for intrahepatic cholangiocarcinoma. World J Hepatol. 2020;12(10):693-708. doi:10.4254/wjh.v12.i10.693

93. Kato A, Shimizu H, Ohtsuka M, et al. Downsizing chemotherapy for initially unresectable locally advanced biliary tract cancer patients treated with gemcitabine plus cisplatin combination therapy followed by radical surgery. Ann Surg Oncol. 2015;22: 1093-1099. doi:10.1245/s10434-015-4768-9

94. Le Roy B, Gelli M, Pittau G, et al. Neoadjuvant chemotherapy for initially unresectable intrahepatic cholangiocarcinoma. Br J Surg. 2018;105(7):839-847. doi:10.1002/bjs.10641 
95. Gemcitabine, cisplatin, and nab-paclitaxel before surgery in patients with high-risk liver bile duct cancer. Available from: https:/clinicaltrials.gov/ct2/show/NCT03579771. ClinicalTrials. gov Identifier: NCT03579771. Accessed September 23, 2021.

96. Hyder O, Marsh JW, Salem R, et al. Intra-arterial therapy for advanced intrahepatic cholangiocarcinoma: a multi-institutional analysis. Ann Surg Oncol. 2013;20(12):3779-3786. doi:10.1245/ s10434-013-3127-y

97. Riby D, Mazzotta AD, Bergeat D, et al. Downstaging with radioembolization or chemotherapy for initially unresectable intrahepatic cholangiocarcinoma. Ann Surg Oncol. 2020;27 (10):3729-3737. doi:10.1245/s10434-020-08486-7

98. Konstantinidis IT, Koerkamp BG, Do RKG, et al. Unresectable intrahepatic cholangiocarcinoma: systemic plus hepatic arterial infusion chemotherapy is associated with longer survival in comparison with systemic chemotherapy alone. Cancer. 2016;122 (5):758-765. doi:10.1002/cncr.29824

99. Edeline J, Benabdelghani M, Bertaut A, et al. Gemcitabine and oxaliplatin chemotherapy or surveillance in resected biliary tract cancer (Prodige 12-accord 18-Unicancer GI): a randomized phase III study. J Clin Oncol. 2019;37(8):658-667. doi:10.1200/JCO.18.00050

100. Primrose JN, Fox RP, Palmer DH, et al. Capecitabine compared with observation in resected biliary tract cancer (BILCAP): a randomised, controlled, multicentre, phase 3 study. Lancet Oncol. 2019;20(5):663-673. doi:10.1016/S1470-2045(18)30915-X

101. Stein A, Arnold D, Bridgewater J, et al. Adjuvant chemotherapy with gemcitabine and cisplatin compared to observation after curative intent resection of cholangiocarcinoma and muscle invasive gallbladder carcinoma (ACTICCA-1 trial) - a randomized, multidisciplinary, multinational phase III trial. BMC Cancer. 2015;15(1):1-8. doi:10.1186/s12885-015-1498-0
102. Nakachi K, Konishi M, Ikeda M, et al. A randomized Phase III trial of adjuvant S-1 therapy vs. observation alone in resected biliary tract cancer: japan Clinical Oncology Group Study (JCOG1202, ASCOT). Jpn J Clin Oncol. 2018;48(4):392-395. doi:10.1093/jjco/hyy004

103. Rahnemai-Azar AA, Abbasi A, Acher AW, Weber SM, Pawlik TM. Emerging pathways for precision medicine in management of cholangiocarcinoma. Surg Oncol. 2020;35:47-55. doi:10.1016/j.suronc.2020.08.008

104. Rahnemai-Azar AA, Pawlik TM. Cholangiocarcinoma: shedding light on the most promising drugs in clinical development. Expert Opin Investig Drugs. 2021:1-9. doi:10.1080/13543784.2021. 1897103

105. Saborowski A, Lehmann U, Vogel A. FGFR inhibitors in cholangiocarcinoma: what's now and what's next? Ther $A d v$ Med Oncol. 2020;12(6):175883592095329. doi:10.1177/17588 35920953293

106. Crispo F, Pietrafesa M, Condelli V, et al. IDH1 targeting as a new potential option for intrahepatic cholangiocarcinoma treatmentcurrent state and future perspectives. Molecules. 2020;25 (16):1-23. doi:10.3390/molecules25163754

107. Blechacz B. Cholangiocarcinoma: current knowledge and new developments. Gut Liver. 2017;11(1):13-26. doi:10.5009/gnl1 5568

108. Okamoto E; Liver Cancer Study Group of Japan. Classification of primary liver cancer. First English edition. Kanehara, Tokyo; 1997:8-40.

109. Shimada M, Yamashita Y, Aishima S, Shirabe K, Takenaka K, Sugimachi K. Value of lymph node dissection during resection of intrahepatic cholangiocarcinoma. Br J Surg. 2001;88(11):14 63-1466. doi:10.1046/j.0007-1323.2001.01879.x

\section{Publish your work in this journal}

Hepatic Medicine: Evidence and Research is an international, peerreviewed, open access journal covering all aspects of adult and pediatric hepatology in the clinic and laboratory including the following topics: Pathology, pathophysiology of hepatic disease; Investigation and treatment of hepatic disease; Pharmacology of drugs used for the treatment of hepatic disease. Issues of patient safety and quality of care will also be considered. The manuscript management system is completely online and includes a very quick and fair peer-review system, which is all easy to use. Visit http://www.dovepress.com/ testimonials.php to read real quotes from published authors. 